\title{
Children's Mental Health in the Era of Globalisation: Neo-Liberalism, Commodification, McDonaldisation, and the New Challenges They Pose
}

\author{
Sami Timimi \\ University of Lincoln \\ United Kingdom
}

\section{Introduction}

Children and families across the world face a multitude of ever changing challenges that will affect their sense of emotional well-being. Dilemmas for children in the first world include: competition, consumerism, individualism, narcissism and family breakdown contributing to children as consumers, the erosion of collective (social) responsibility, dislocation, alienation, inequality, relative poverty, and crime. Dilemmas for children in the third world include: regional wars and conflict, ecological catastrophe - man-made and natural contributing to material poverty, lack of state resources (e.g. medical), migration, fragmentation of communities, disease, malnutrition, and crime. Each society has its own mechanisms to promote the natural resilience of children and families in the face of each individual, family and society's unique challenges. The era of globalisation has resulted in the global exchange of not only goods, but also ideas and values, resulting in new challenges. Aggressive free market global economic systems contribute to the creation of new dangers. The development of universalised therapeutic approaches has inadvertently replicated colonial dynamics by imposing Western notions of self, childhood, and family onto non-Western populations. Globalisation also brings new opportunities for new identities, fusions and creative solutions.

A variety of economic, political, and cultural pressures shape beliefs and practices around children and families. Policies that promote a particular form of aggressive capitalism lead to a narcissistic value system that permeates social institutions, including those that deal with children. Not only does this impact children's emotional well-being, but it also shapes the way we conceptualise children and their problems. These beliefs and practices have facilitated the rapid growth of child psychiatric diagnoses and the tendency to deal with aberrant behaviour or emotions in children through technical - particularly pharmaceutical - interventions, a phenomenon I refer to as the 'McDonaldization' of children's mental health. Diagnoses do not yet reveal the causes of mental difficulties or provide clear differentiators for treatment. As subjective constructs they are thus vulnerable to 'commodification' processes. Commodification can distance people from a more considered in-depth understanding of the problems being experienced. Thus, unlike diagnoses that are 
attached to a pathophysiological aetiology and/or differential treatment indicators that effect outcomes, there is little evidence to support the contention that long-term prognosis for child mental health problems have improved.

The present chapter seeks to challenge many of the cultural assumptions regarding childhood embedded within the narrow biomedical frame currently dominant in mainstream child and adolescent psychiatry and explores the connections between economy, politics, culture, globalisation, and children's mental health. Implications for child and adolescent mental health practice and suggestions for adopting a more context rich perspective will be outlined.

\section{Contrasting beliefs}

Teachers in an inner London school become concerned about a fourteen-year-old girl whose parents come from the Indian sub-continent. She has been behaving, in their opinion, 'bizarrely' for some days now, laughingly inappropriately at times; appearing preoccupied, and has stopped mixing with her peers. An urgent psychiatric assessment is arranged and the psychiatrist concludes that this young adolescent is suffering from a psychotic illness and requires admission to a psychiatric unit for treatment with anti-psychotic medication. However, her parents and the young adolescent herself disagree, claiming that, in their opinion she is not 'ill' but suffering the manifestations of a spiritual problem as they consider it is likely that she has become possessed by evil spirits. What they feel she needs is a consultation with a local 'priest' to ascertain the nature of the current spiritual crisis.

Cases such as the above, increasingly encountered in clinical practice in multi-cultural societies such as those in modern Europe and North America, raise clinical and ethical dilemmas. Whose version should we believe? Can either version (that she is mentally ill or that she is possessed by bad spirits) claim any objective evidence to support its case? Should the beliefs of the more powerful party (in this case the psychiatrist and to a lesser extent the teachers) impose their view of the problem on this young lady and her family? To what extent should the professionals take into account the young lady and her family's beliefs about the nature of her problems, and how might they work with this? Indeed, do scenarios such as the above present new opportunities for professionals to learn new ways of working from communities considered in many ways to be culturally inferior and whose belief systems professionals therefore often dismiss? Whilst clinicians may rightly assert that they need more information in order to come to a pragmatic conclusion on how to proceed, the advantage of stripping away extra details is that it exposes starkly opposing views that don't disappear within the extra layers of complexity surrounding any case. These questions are of more importance than just that of passing philosophical and academic interest as incompatible belief systems between users and professionals have been shown to have potentially fatal consequences (Smith, 2003). Further, these clinical, ethical, and philosophical questions are not limited to those with the most 'extreme' presentations, but are relevant across the spectrum of mental health in the young, including our approaches to child development and child protection (Maitra, 1996; Timimi, 2002; 2005a; 2005b; Timimi \& Maitra, 2006).

A psychiatric trainee of Nigerian origin starting her second year of psychiatry training in the UK commences in her first placement in a child and adolescent mental health service. She observes her supervising consultant psychiatrist conducting the first three assessments she 
has witnessed. She later confesses in a private conversation with a sympathetic colleague that she could not see anything 'abnormal' in the referred children's behaviour, and could not understand why these children needed to be dealt with by the medical profession and why each received a psychiatric diagnosis.

The easiest way for a professional to deal with the ambiguities in the two scenarios above, is to avoid questioning the basis on which the assumptions of the dominant ideology is based and instead side with the moral certainties that a universalising approach to problems of mental health the psychiatric belief system provides. However, the problematic nature of such an approach can be found in even what might seem areas where certain cultural beliefs and practices appear clearly unethical and unacceptable. For example, Kaplan (1997) in her discussion of the film Warrior Marks (a film that is a graphic critique of clitoridectomies in Africa, dramatising the pain and terror involved), noted that the adult African woman in the film, defend clitoridectomies as a necessary part of their tradition and sacred practices. Kaplan makes the point that the film argues against clitoridectomy at the expense of African women's (in the film) beliefs, reproduces the imperialist tradition of teaching Africans a better way of living, relies on established stereotypes of Africans as exotic and potentially savage, and finally assumes a global women's rights approach. Whilst it is important to acknowledge that many Africans in a variety of countries are actively working toward abolishing this procedure (e.g., Cook et al., 2002), it is also vital not to frame these complex issues in a one-sided manner by imposing the value system of one culture upon another. After all one wonders what many of these African women might think about the ease with which women in the West use a variety of cosmetic surgeries to make them more attractive and appealing. Premature closure of on-going debates is likely to result in entrenched positions rather than meaningful dialogue.

Similar problems with a universal approach to children's rights can also be found. For example Segal (1992) found that health and social work professionals in India and America saw child abuse in very different terms. Indian professionals' more than American ones considered a wider range of adult sexual behaviours and media images seriously abusive to children. However, Indian professionals did not consider physical 'maltreatment' to be as seriously abusive as their American counterparts did.

Certain writers have tried to resolve some of these issues, for example Finkelhor and Korbin (1988) argue that certain cultural practices such as scarification which confers identity in tribal groups can be viewed as non-abusive as opposed to others such as clitoridectomy which can be viewed as abusive because the latter increase morbidity and certain ethical/moral/human rights standards are violated. This argument still remains suspect, however, as it draws on an ethical framework to make this separation and the question then becomes who is it that sets these standards and decides what is acceptable morbidity (Maitra, 1996). If we are to apply such standards universally, how much of current Western psychiatric practices could then be viewed as unethical? After all there is known morbidity, including fatalities, associated with the use of psychiatric medication for childhood behaviours that other cultures may not see as being at all problematic or abnormal amongst the young (Timimi, 2005a; 2008a).

\section{Contrasting childhoods}

Whilst the immaturity of children is a biological fact, the ways in which this immaturity is understood and made meaningful is a fact of culture (Prout \& James, 1997). Members of any 
culture hold a working definition of childhood, its nature, limitations and duration based on a network of ideas that link children with other members of society and with the social ecology (Harkness \& Super, 1996). While they may not explicitly discuss this definition, write about it, or even consciously conceive of it as an issue, they act upon these assumptions in all of their dealings with, fears for, and expectations of, their children (Calvert, 1992). In addition, different social practices of different cultures produce different childhoods each of which are 'real' within their local regime of truth (Prout \& James, 1997; Stephens, 1995). As a result it has been argued that in any culture, children and then adults come to acquire their subjective selves through incorporation of values, beliefs and practices that sustain the desired social relationships of that culture (Althusser, 1969).

People, 'know' themselves through the mediation of ideological institutions and some of the most important of these institutions, such as schools, focus their attention on children. As Rose (1999) points out, "Individuals act upon themselves and their families in terms of the languages, values and techniques made available to them by professions, disseminated through the apparatuses of the mass media or sought out by the troubled through the market." (Rose, 1999: 88) The implication is that we cannot just take at face value that individual actions evolve only from innate desires. Desires grow from norms and regulations. At the same time there is a danger in such a perspective of falling into a socially deterministic ideology; thus even though a person's experience depends on the prescriptions of the day, agency does play its part. As Martin \& Sugarman (2000) claim, that "While never ceasing to be constructed in sociocultural terms, psychological beings, as reflection-capable, intentional agents, are able to exercise sophisticated capabilities of memory and imagination, which in interaction with theories of self can create possibilities for present and future understanding and action that are not entirely constrained by past and present sociocultural circumstances." (Martin \& Sugarman, 2000: 401).

Such an ecological framework, that includes an appreciation of the intentional person making sense of the reality from within their broader social, political and cultural context, makes it difficult to pass a value or scientific judgment about whether children are better or worse off in any particular culture or society, as the idea that there are universal ideals or natural unfolding process that all children should be able to achieve, becomes suspect. Nonetheless, this position also understands that children are socialised by belonging to a particular culture at a certain stage in that culture's history, so certain differences in children's behaviour can be seen as a result of different child rearing philosophies, socialisation processes, and political realities. We can, therefore, make some comparisons, whilst keeping in mind the above caveats and indeed using them to help us 'interrogate' any naïve or romanticised assumptions.

\section{Western childhoods}

The space of childhood in contemporary Western culture has witnessed rapid changes that effect children. Well-documented changes include (Timimi, 2010):

1. Children's diets (which have increased in sugar, saturated fats, salt, chemical additives and decreased in certain essential fatty acids and fresh fruit and vegetables);

2. Family structure (which has seen the demise of the extended family, increase in separation and divorce, increase in working hours of parents, and a decrease in the amount of time parents spend with their children); 
3. Family lifestyle (there has been an increase in mobility, decrease in 'rooted' communities, and an increasing pursuit of individual gratification);

4. Children's lifestyle (which has witnessed a decrease in the amount of exercise, the 'domestication' of childhood due to fears about the risks for children resulting in more indoor pursuits such as computers, virtual socialisation through 'Facebook' and the like, and TV);

5. The commercialisation/commodification of childhood (increase in consumer goods targeted at children and the creation of new commercial opportunities in childhood, for example the 'parenting' industry and the pharmaceutical industry) and;

6. Changes in the education system (modern teaching ideology is rooted in methods such as continuous assessment and socially orientated worksheets that some argue favour the learning style of girls over boys (e.g. Burman, 2005)).

These changes are occurring at a time when our standards for what we consider to be acceptable behaviour in the young and acceptable child rearing methods are both narrowing. It is now harder than ever to be a 'normal' child or parent (Timimi, 2005a; 2009a).

\subsection{Rising rates of mental disorders in the young}

In parallel with this, evidence from longitudinal studies show rising rates of 'mental' disorders among the young (such as emotional, anxiety, eating, and behavioural disorders) in the past few decades (British Medical Association, 2006) despite the perception that recent generations have 'never had it so good'. Cross-cultural research finds considerable differences in prevalence rates for psychiatric disorder, with children, particularly boys, in politically stable developing countries appearing to have considerably lower rates of behavioural disorders than in Western societies (e.g., Cederblad, 1988; Pillai et al., 2008). Figures for prescriptions of psychotropic medication to children and adolescents both illustrate the depth of this problem and our peculiar cultural style of responding to it.

Of particular concern is the increase in rate of stimulant prescription to children. By 1996 over $6 \%$ of school-aged boys in America were taking stimulant medication (Olfson et al, 2002) with children as young as two being prescribed stimulants in increasing numbers (Zito et al., 2000). Surveys in the late 1990s showed that in some schools in the US over 17\% of boys were taking stimulant medication (LeFever et al, 1999) and recent estimates suggest that about $10 \%$ of school boys in the US have been or are being prescribed a stimulant (Sharav, 2006). Between 1991 and 2010, prescriptions in the USA of stimulants increased from 5 million to 45 million, a 9-fold increase (National Institute of Drug Abuse, 2011). In the UK prescriptions for stimulants have increased from about 6000 prescriptions a year in 1994 to over 450,000 by 2004; a staggering $7000 \%$ rise in one decade (Department of Health, NHSE, 2005) with figures continuing to increase, reaching over 800,000 by 2009 (NHS Information Centre, 2010). These trends are being replicated across other psychotropic medications too (Timimi, 2009b).

These rapid changes in practice in the area of children's mental health have not come about as a result of any major new scientific discovery (see Timimi, 2002; 2004; 2005a; 2009; Timimi \& Maitra, 2006). There are two other possibilities that could explain these increases. The first is that there has been a real increase in emotional and behavioural disorders in children 
leading to greater public scrutiny and concern about such behaviours which, in turn, has resulted in a greater professional effort to understand and alleviate these behavioural and emotional problems. The second possibility is that there has not been a real increase in emotional and behavioural disorders in the young but there has been a change in the way we think about, classify, and deal with children's behaviour - in other words our perception of and the meaning we ascribe to children's emotions and behaviour. Both possible causes for the rapid increase in our identification of and treatment for mental health disorders in the young require an examination of contexts. Indeed the third, and in my opinion, most likely possibility that explains the increase is an interaction between the aforementioned two possibilities. In other words, it could be that changes in our cultural/environmental contexts are causing increases in certain emotional and behavioural problems and these, in turn, are changing our perception of and the meaning we give to childhood behaviour. For example, an increase in certain behaviours will lead to increasing levels of anxiety about the long term consequences of these behaviours leading to greater scrutiny, study, and attempts at intervening to change these behaviours. This process then changes the way view childhood behaviour and our common cultural practices around children (such as child rearing and education), and by further increasing our anxieties and scrutiny of these behaviours we begin to 'pathologise' behaviours that previously would not have aroused such anxieties.

In examining these trends, two aspects of the Western value system that have become embedded in our daily discourse due, at least in part, to our reliance on rather aggressive forms of neo-liberal free market principles, deserve further scrutiny. These are the problems of 'narcissism' and 'commodification'. Narcissism describes the character trait of 'self love' or in the more everyday sense 'looking after number one'. The spread of narcissism has left many children in a psychological vacuum, pre-occupied with issues of psychological survival and lacking a sense of the emotional security that comes through feeling you are valued and thus have an enduring sense of belonging. The growth of narcissism contributes to the growth of behavioural and emotional problems in the young. Commodification refers to the process by which goods, ideas, indeed anything can become a 'thing' with a commercial value that can be bought and sold, and subject to the influence of the market, which then makes it available for exploitation. Childhood, parenting, children's distress and professional approaches to intervening in this have, I will argue, all become subjects of 'commodification'. The growth of commodification contributes to both an increase in certain behavioural problems and the continual expansion of the repertoire of behaviours and emotional states found in children that are considered to be 'abnormal'.

\subsection{The impact of growing up in a narcissistic value system}

One of the dominant themes used by advocates of neo-liberal free market economy ideology is that of 'freedom'. At the economic level this is a core requirement of free market ideology. Companies must be as free from regulation as possible to concentrate on competing with others, with maximizing of profits the most visible sign of success. There is little to gain from social responsibility (only if it increases your 'market share'). At the emotional level the appeal to freedom can be understood as an appeal to rid us of the restrictions imposed by authority (such as parents, communities and governments) (Richards, 1989). By implication this value system is built around the idea of looking after the wants of the individual - narcissism. Taking this a step further, once the individual is freed from 
authority they are (in fantasy at least) free to pursue their own individual self-gratification desires, free from the impingements, infringements and limitations that other people represent. The effect of this on society is to atomise the individual and insulate their private spaces to the degree where obligations to others and harmony with the wider community become obstacles rather than objectives. In this 'look after number one' value system, other individuals are there to be competed against as they too chase after their personal desires. This post second world war shift to a more individualistic identity was recognized, as early as the mid-1950s, by commentators who first spoke about how the new 'fun based morality' (Wolfenstein, 1955) was privileging fun over responsibility - having fun was becoming obligatory (the cultural message becoming that you should be ashamed if you weren't having fun). With the increase in new possibilities for excitement being presented, experiencing intense excitement was becoming more difficult, thus creating a constant pressure to push back the boundaries of acceptable and desirable experiences, and lifestyles, opening the doors, amongst other things, to sub-cultures comfortable with drinking to excess, violence (for pleasure), sexual promiscuity, and drug taking.

In this value system others can more easily become objects to be used and manipulated wherever possible for personal goals and thus social exchanges become difficult to trust as the better you are at manipulating others the more financial (and other narcissistic) rewards you will get. Such a value system, which ultimately seeks to eradicate or at least minimize social conscience as a regulator of behaviour, cannot sustain itself without the moral conscience beginning to feel guilty (Richards, 1989). Thus it is no coincidence that those who are the most vociferous advocates of free market ideology tend also to advocate the most aggressive and punitive forms of social control. Thus another hallmark of Western culture's increasing psychological reliance on developmentally immature impulses that encourages it to avoid taking responsibility for its beliefs and practices, is the so called 'blame culture', which fills the media and contemporary discourse more generally. In addition, Western politicians, who act as advocates for this system, repeatedly use childhood, the family and 'traditional values' as rhetorical devices to shore up the 'free' market ideology. Throughout the past few centuries, at regular intervals and particularly at times of economic uncertainty and social unrest, calls are made by the ruling classes to 'return' to traditional values (Harvey, 2010), passing responsibility for addressing the behavioural problems away from the structural inequalities necessary for a market economic system to successfully compete in the global market, back to parents who are criticised for not doing a better job of disciplining their children.

With narcissistic goals of self-fulfilment, gratification and competitive manipulation of relationships so prominent, together with the discouragement of the development of deep interpersonal attachments from which a sense of social responsibility arises, it is not difficult to see why so-called narcissistic disorders (such as anti-social behaviour, substance misuse, and eating disorders) are on the increase (Dwivedi, 1996). A heightened concern for the self can be both 'liberating' and simultaneously oppressive.

Children are cultured into this value system by virtue of living within its institutions and being exposed daily to its discourse. Although none of us are one dimensional in our experiences or our interpretation of them, a narcissistic value system helps create an environment of winners and losers, a kind of survival of the fittest where compassion and concern for social harmony contradicts the basic goal of the value system. As this system is 
showing itself to be bad for children's happiness a similar process as above works to try and distance us from the anxiety arising from the guilt thus produced. Instead of asking ourselves painful questions about the role we may be playing in producing this unhappiness, we can view our children's difficulties as being the result of biological diseases that require medical treatments (we can blame their genes) (Timimi, 2008b). This gives governments new ways of regulating the population, with biological models of psychiatry providing convenient ways to subcategorise discontent and behavioural deviance making 'divide and rule' easier (Moncreiff, 2008).

\subsection{Surveillance, commodification, and McDonaldisation}

The dynamics involved in concepts of self being shaped in a narcissistic direction, interacting with the collective guilt and fear of retribution and becoming a loser in the competition, means that governments feel the need to police potentially dangerous selves that may thus emerge, in an increasing variety of ways. Thus, one other feature that has changed dramatically over the past century of Western society is the amount of surveillance to which parents and their children are subjected. The state has all sorts of mechanisms of surveillance and an 'army' of professionals tasked with monitoring and regulating family life. This is not to say that we do not need surveillance as the effects of, for example, uninterrupted traumatic events such as child abuse can be many and far reaching, thus robust child protection services and legislation are vital in any society that wishes to claim that it takes childhood welfare seriously. But we must also ask questions about the what we chose not to notice (such as structural and social inequalities) in carrying out such surveillance, at the same time as understanding the potential impact of how we decide to do this on children, families and our culture more generally.

The increase in levels of anxiety amongst parents who may fear the consequences of their action, has reached the point where the fear for many is that any influence that is discernible may be viewed as undue influence. This increases the likelihood that parents will leave essential socialising and guidance to the expertise of professionals as, surrounded by a discourse that paints childhood and child rearing as loaded with risk, they lose confidence in their own abilities (Maitra, 2006). The increase use of medical explanations for behavioural problems has far reaching effects changing our ideas about free will, choice and personal responsibility for our behaviour. For example, if impulsive and aggressive behaviour by a child is viewed as being caused by a brain disorder called Attention Deficit Hyperactivity Disorder (ADHD), then it is considered to be behaviour that a child or their parent cannot consciously control and one that requires medical assistance to remedy (assuming of course it has been decided that the behaviours need to be changed), thus shifting activities previously considered pedagogic and the remit of parents and teachers into the medical arena (Tait, 2006).

Into this anxiety loaded, narcissistically pre-determined vision of childhood and practices of child rearing, new diagnoses (such as childhood depression, ADHD, Aspergers syndrome) appear to provide a temporary relief to the beleaguered, intensely monitored child carers. Viewing children's poor behaviour and distressed emotional state as being caused by an 'illness' apparently spare all from further scrutiny. The result however, fits into another aspect of our 'fast culture'. With the widespread application of the techniques of medicine to manage our children's behaviour and emotional state, particularly through use of drugs, we 
have achieved what I call the 'McDonaldisation' of children's mental health. Like fast food, recent medication centred practice came from the most aggressively consumerist society (USA), feeds on peoples desire for instant satisfaction and a 'quick fix', fits into a busy lifestyle, requires little engagement with the product, requires only the most superficial training, knowledge and understanding to produce the product, creates potential lifelong consumers of their products, and has the potential to produce damage in the long term to both the individuals who consume these products as well as public health more generally.

It is no accident that such forms of practice have emerged most prominently in those countries, such as the USA, that are the strongest advocates of the neo-liberal market system. Such societies are characterised by a consumer culture. As such the culture is driven by the social arrangement in which the buying and selling of goods and services is not only the predominant activity of everyday life but is also an important arbiter of social organisation, significance and control. Slater (1997: 101) has commented that today "more of social life is produced in a thing-like form" and this notion of a 'thing-like form' fits well as a way of thinking about how diagnosis and professional practice in mental health often views mental distress and behavioural deviance. Commodification entails processes of abstraction that not only creates a 'thing', but, specifically, a commoditised 'thing' that can enter into the market. Castree (2003: 281) describes abstraction as the process by which "the qualitative specificity of any individualised thing (a person, a seed, a gene or what-have-you) is assimilated to the qualitative homogeneity of a broader type or process." Thus diagnostic categories relegate markers of individual differences to ones of lesser significance and instead promote a more uniform and standardised 'type', which is clearly easier to 'package', promote and sell. Robertson (2000) developed the concept of 'functional abstraction' to refer to circumstances where individual cases are considered as 'instances' of the generic category, which stands over and above them. For example, Robertson (2000:472) in exploring the formal assessment methodologies and taxonomic systems which work to commodify 'wetlands', comments: "Taxonomic classification systems provide both an imposed order and a common language for scientists [...] assessment methodologies involve paper forms, filled out on a brief visit to a site, which allow the assessor to total up a 'score' for a given site" (Robertson (2000: 473), an observation that could just as easily be applied to diagnostic practice.

As psychiatric diagnostic categories are built on a subjective basis and have as yet not been found to attach to any physical markers to support their existence as 'natural' biologically congruent entities, they are ripe for exploitation as a commodity. Childhood distress was once the remit of parents and families to deal with and in most parts of the world this remains the case. However, once this responsibility begins to migrate into being the remit of a professional class whose livelihood is based on an 'expertise' in alleviating childhood distress and preventing behavioural deviance, and when this occurs in a 'free' market context, then commodification is just around the corner. Once we have categorised states of emotional and behavioural deviance and these categories enter the market, they become the equivalent of brands. Each brand will develop a market including professionals (with expertise in the brand) and treatments (such as a particular medication or a particular form of psychotherapy). Consumers will be largely made of parents, who (partly as a result of the dynamics mentioned above) have come to be concerned that their child has a problem and that this problem is beyond their capability to resolve. However, it is not just parents, but layers of social pressures and cultural beliefs (in the shape of, for example, politicians, family practitioners, social workers, teachers) that play an important role directly as 
consumers for children under their authority or as consumer advocates encouraging parents to become consumers. These consumers now seek out a product (a diagnosis, an expert, a treatment) based on the information they receive (from advocates, media and a variety of marketing sources) in the hope that the product will offer a form of 'validation' (of the struggles and anxieties being experiencing) and/or a sense of 'promise' (having the 'product' or brand such as a diagnosis will lead to an improvement in their life). Like all commodities the appeal is more at the emotional/desire level than the rational one.

Once this system is set in motion we can predict a number of things will happen. Commodities tend to give only temporary experiences of satisfaction as markets must keep selling to keep the monetary flow going and so must keep convincing consumers that there is a better 'brand' waiting for them. In other words, once an area of life has been subject to market commodification, we should predict that the market will grow in volume as new products and competitors enter the fray. Thus the number of available psychiatric diagnostic categories has continued to expand, both in the 'official' manuals and in everyday practice. Not only do new categories emerge but so do new subcategories, number of professionals providing services, the number of professionals with specialisations and sub-specialisations, the number of treatment models (for example we have well over 400 systematised models of psychotherapy), and so on (Double, 2002). There is now a bewildering array of commodities out there for the concerned parent to try and access. Yet, unlike the rest of medicine where diagnostic categories have largely developed around an aetiological basis and where treatments have demonstrated sustained improvements in outcomes for patients, there is little encouraging news for long term mental health outcomes and some potentially discouraging ones (Whitaker, 2010). Like any market there are periods of over-consumption resulting in cut-backs and a pruning off of some competitors. Likewise commodities can be subject to the changing whims of the producers and consumers as certain products go in and out of 'fashion' (such as 'autism' is the new 'ADHD'!). However, as a relatively young market the globalisation of this 'McDonalisation' of children's mental health has only just started. The owners of these new products (largely institutional psychiatry and psychology based in the West and in partnership with the financial and marketing prowess of the Pharmaceutical industry) are only just beginning the mass export and globalisation of this market and all the ideological implications this contains (Timimi, 2009c).

\subsection{Family life and children's rights}

The increase in working hours, increased inequality in incomes, greater job insecurity, and the breakdown of contacts with extended family in the context of a cultural drive toward individual aspirations and consumerism also has a direct impact on the mental health of children. Many studies have documented an association between poverty, marital disruption, and a wide range of deleterious effects on children's behaviour and emotional state (e.g. McMunn et al, 2001). Children, who live with a lone parent, with unemployed parents, parents on low incomes, and families living in public sector housing, are at higher risk of developing emotional and behavioural disorders (Dodds, 2005). Pressures on working mothers can be particularly intense with those who strive to be so-called 'supermums' expecting to be able to seamlessly blend their working life and parenting, being most at risk of depression (University of Washington, 2011). Parental stress and depression is known to adversely impact infants and children in a variety of ways including, 
interpersonal communication, emotional expressiveness and responsiveness, withdrawal, and disengagement with their children, with social adversity compounds these effects (Timimi \& Dwivedi, 2010).

Social inequality seems a powerful mediator of mental distress and dissatisfaction. In the last few generations, we have seen many changes in the way we interact with each other both within and without our atomized family units. Increasingly, mental well-being seems closely linked to how well one is able to compete in highly inegalitarian societies. Thus a recent World Health Organization (Friedli, 2009) report concluded: "It is abundantly clear that the chronic stress of struggling with material disadvantage is intensified to a very considerable degree by doing so in more unequal societies. An extensive body of research confirms the relationship between inequality and poorer outcomes, a relationship, which is evident at every position on the social hierarchy and is not confined to developed nations. The emotional and cognitive effects of high levels of social status differentiation are profound and far reaching: greater inequality heightens status competition and status insecurity across all income groups and among both adults and children. It is the distribution of economic and social resources that explains health and other outcomes in the vast majority of studies." (Friedli, 2009: III)

Surveys for childhood well-being consistently put those countries that pursue the most aggressive neo-liberal policies (such as the UK and the USA) at the bottom of league tables for the developed world (e.g. UNICEF, 2007). A recent report of an in-depth comparison of children's experiences across three developed countries - the UK, Sweden and Spain emphasised the impact of consumerism and economic inequality. It found that children in the UK (bottom of the 2007 UNICEF table on childhood wellbeing) feel 'trapped' in a materialistic culture and don't spend enough time with their families. Children in all three countries told researchers that their happiness is dependent on having time with a stable family and plenty of things to do, especially outdoors, rather than on owning material goods. Despite this, parents in the UK said they felt pressure from society to buy goods for their children with this pressure felt most acutely in low-income homes. As UK parents often felt they lose out on time together as a family, due in part to long working hours, they often tried to make up for this by buying material things for their children (UNICEF, 2011).

The guilt that all this causes, both at the individual level and societal level, spurs on an industry of 'child savers', campaigning for greater protection of children and ever-greater surveillance of family life. In recent years, advocates of this 'children's rights' movement have focussed their campaigns on trying to get governments to outlaw the physical punishment of children, often citing Sweden as a positive example. Yet an examination of various morbidity and mortality figures shows Swedish children to be somewhere in the middle of league tables for rich countries (Beckett, 2005). For example, rates of death from child maltreatment in Sweden at 0.6 per 100,000 children is much higher than countries who fare best in these tables, namely Spain (at 0.1) and Greece and Italy (at 0.2) (UNICEF, 2001) who have not outlawed corporal punishment (but who interestingly have family orientated cultures). The problem with this approach to protecting children is that the focus on individual perpetrators permits complacency about the collective responsibility of governments and their institutions, for allowing environments that cause other forms of harm to develop. Children's rights have regularly emerged as an issue in the history of the developed/industrialised nations. Exploitation for profit is the guiding rule of a market led economy and children have often been the subjects of such exploitation. Children's rights 
movements then appear at regular intervals with the focus of protest shifting, from child labour to the commercialisation of childhood to child abuse. However, whilst the focus is on saving the individual child, important as this is, it can distract from appreciating the degree to which children's rights are intertwined with the political and social pressures of that society and the degree to which the economic system may exploit them.

Thus, many children in the West grow up with an experience of childhood that is shaped by emotional insecurity and unhappiness, conflict, and competitiveness, in a context where their (and their families) behaviour is subject to a great deal of surveillance, exploitation of emotional desires, and insidious social control. Of course such generalisations need qualifying as they are just that - generalisations - arising from a particular interpretation of the current challenges facing children growing up in what psychologist Oliver James calls 'selfish capitalism' (James, 2007). We must remember that Western societies are not one homogenous mass, but encompass large diversities of ethnicity, class, location, social capital, climate, and services to name but a few. Whilst understanding the 'general' may help to understand the 'particular' it is no substitute for this, as staying at the level of the general, risks falling into unhelpful stereotypes.

\section{Non-western childhoods}

Any attempt to encompass the history, politics, and religion, not to mention psychology, of any culture or region is always going to be only partially successful. It would also be wise to be cautious of an analysis of cultural difference that relies on attractive and convenient polarized dichotomies that gloss over enormous intra-cultural differences and problematic local beliefs that cause suffering to their populations such as female infanticide and selfimmolation (Lari et al, 2005; Banhatti et al, 2006).

As with generalisations about the impact of neo-liberal market dominated philosophies on children and families, there are also obvious limitations when making generalised statements about cultural beliefs and practices in the non-Western world. Nonetheless it is possible to note that some general differences can be found. Broadly speaking the predominant differences between non-Western and Western approaches to children is visible in the prolonged indulgence accorded to infants, and in the earlier acceptance of certain adult responsibilities in the children of many non-Western cultures. Thus, in many Western cultures the search for evidence of independence, self-reliance, and self-control starts more or less as soon as the child is born, while many non-Western cultures promote emotional dependence through immediate gratification of an infant's perceived needs. As the child grows older in Western culture independence is encouraged in thinking style, verbal communication, and emotional expression. Physical labour and the acceptance of duties and responsibilities do not occur until much later in Western than many non-Western cultures. In many non-Western cultures adolescence as a clear life stage with its own subculture is not so readily apparent, while a movement into adult duties and responsibilities (that include the products of a child's physical labour, as well as an early introduction to spiritual duties) may be already apparent before the onset of puberty. Many of these differences arise from a social orientation toward the 'individual' in Western cultures and toward the 'collective' in many non-Western cultures. This, at least in part, reflects the differing aims of many non-Western cultures where the ideologies behind parenting practices reflect the aim of helping the child transcend egotistic narcissism and toward the 
cultivation of dependability and interdependence, rather than towards independence as in the West (Timimi, 2005a; 2005b).

\subsection{Models of child development}

Long established theories and practices with regard child development have extensive histories in many non-Western traditions. For example, in traditional Indian thinking the human life cycle is conceptualised as unfolding in a series of stages each having unique tasks. Traditional Indian medicine and philosophy in the form of Ayurveda describes childhood Samskaras (which are expressive and symbolic performances) including rites and ceremonies that are held over the child to mark her/his transition from one stage to another (Kakar, 1994; 1997). Middle Eastern culture is heavily influenced by Islamic ideas on child development, which has been debated by Islamic scholars over many centuries (Gil'adi, 1992). Emphasis is placed on learning about the social values of Islam such as cooperation, truthfulness, helping the elderly, obeying parents, systems of spiritual purity and pollution, and the importance of cleanliness of the body. Various stages of cognitive development are identified, which revolve around sophisticated concepts such as Tamyiz (facility for discernment), Addab (respect/ public manners), and aql (mindfulness or social intelligence) the development of which in a child are seen as evidence of readiness to progress to the next developmental phase (Davis \& Davis, 1989; Fernea, 1995; Gregg, 2005; Timimi, 2005a).

These models of child development, when coupled with early 'indulgence' of the infant and an orientation toward group identity and spiritual goals, lead to a high acceptance, low pressure, low competitiveness approach that fosters children's desire to show respect and obedience, as opposed to becoming preoccupied with self esteem as is often the case with children growing up in the Western tradition. Several social and anthropological studies have noted the positive impact this seems to have on children's mental health (Gregg, 2005; Hackett \& Hackett, 1994; Kakar, 1994; Le Vine et al, 1994). There is good evidence that children growing up in such a value system show lower prevalence of mental disorder when compared to Western children (see for example Banhatti \& Bhate, 2002; Banhatti et al, 2006; and Pillai et al, 2008 with regard children from the Indian Diasporas).

There is a general trend in many non-Western cultures toward the welcoming of children into society, greater acceptance of a range of childhood behaviours, and more consensual and hierarchical interpersonal relationships. This is mediated by value systems that place the child firmly in an ecological, spiritual and social context. Children grow up in an atmosphere where they are accepted for just being rather than for achieving certain 'developmental milestones'. Referring to Indian mothers Kakar (1994) and Roland (1980) have commented on the more relaxed attitude about the ages at which they expect children to develop skills. Furthermore, traditional Indian attitudes toward imperfection, disease, and misfortune, encourages an attitude of acceptance rather than seeking to blame, control, or redress; an attitude that can lead to resilience in the face of adversity (Banhatti et al, 2006). As Bhagwat (2002: iv) noted "The child rearing practices and the childcare techniques have been practised over Indian subcontinents for thousands of years from generations to generations with minor changes in different regions and culture. However, no notable bad effects are observed. This has more importance in the light of behavioural disturbances found in children from the so-called developed countries". 
In many cultural settings the self is conceptualized as necessarily existing in a social context. For example, according to the concept of Ubuntu, prevalent in certain parts of Africa, " $a$ person is a person through other persons." In such cultures one can hardly be conceived of as existing as a human being in isolation. Such 'ethno-theories' contribute to shaping child rearing practices by helping to structure the goal of childrearing, its underlying developmental models, and hence the preferred methods and practices. For example, in comparative studies Japanese mothers are found to emphasize harmonious relations through cooperation, compliance, and empathy, while German mothers prefer the developmental goals of independence and individuality, reinforcing their child's autonomy. In case of conflicts, Japanese as compared to German mothers tend to empathize with their child's emotional state and attribute their child's behaviour to positive factors (such as 'a child is only a child'). These ethnotheories are linked to differing models of childhood, child development and child rearing. These models, in turn, lead to variations in childhood experiences. Thus Japanese mothers' approach seems to foster the establishment of a close emotional bond with their children, which helps the child control negative emotions more successfully than is the case for German children (Trommsdorff, 2002).

Thus many non-Western children grow up in contexts where a nurturing and, to many Westerners, an indulgent attitude towards the demands of an infant, is encouraged and where integration into wider society takes place earlier and with recognised stages marked by concrete rituals as they move from one stage to the next. This reflects on, not only their view of themselves as individuals and their aspirations, but also on the behaviour of those around them towards them. In 'collectivist' cultures (i.e. cultures whose value systems are orientated towards the importance of the group as opposed to the individual), people are, from birth onwards, integrated into strong, cohesive groups that continue to offer them protection in exchange for loyalty throughout that person's life (Hofstede, 1994). The sense of ' $w e^{\prime}$ dominates over the sense of ' $\mathrm{I}$ ' with obligations and duties often overriding personal preference in importance (Triandis, 1995).

When functioning well this way of life, provides sufficient emotional security, guidance, and a view of life that makes, for most, displays of defiant and aggressive behaviour less likely. With a greater number of adults available for care, nurturing, friendship, and physical affection and a greater number of peers readily available to entertain them, we have a good model of a system that is arguably better for the emotional nurturing of children than the increasingly fragmented and narcissistic models found in the West (Timimi, 2005a).

\section{Globalisation}

The ever-increasing abundance of global connections and our understanding of them constitute globalisation. This 'compression of the world' has led to an intensification of consciousness of the world and a shortening of distance and time across the globe. Many forces have been at play to bring about the globalisation we are so familiar with today, including the extension of world capitalist economy, industrialization, increasing surveillance (most notable through global information systems) and the world military order (Gidens, 1990; 1991). Global recessions have often hastened globalisation of world economic activity involving the speeding up of production and consumption turnover. 


\subsection{Globalisation from above and the problem of colonialism}

One important aspect of globalisation is the neo-colonial character of the way the world economy has become organised. This economic system has resulted in glaring inequalities between the economically 'developed' and 'developing' worlds and, from a human rights perspective, it can be argued that the global economic system is guilty of on-going and systematic human rights violations and bears a large responsibility for many man made problems, such as poverty, starvation, lack of health care, militarization, and regional conflicts. It is notable that children are often disproportionately affected by famine and morbidity from lack of access to treatment for treatable diseases (such as malaria) and many of the issues above affect their lives directly (for example in many regional conflicts, child soldiers are involved in the fighting). These political, health, and social problems have a direct impact on children's mental health, as a result of factors such as trauma, chronic stress, loss of important people in their family, dislocation, and the effects of becoming accustomed to a life immersed in hardship and violence.

A more subtle impact of the neo-colonial nature of globalisation is the export of Western value systems to countries with value systems born out of different traditions. This can result in undermining the stability of traditional beliefs and practices that have served the children of many communities well, at the same time as producing points of conflict, antagonism and contradiction as the merits of different value systems clash (Ang, 1996). All too often these conflicts are resolved in favour of the more powerful and influential culture (i.e. that of the industrialized West).

These hierarchical dynamics can be found in our popularised visions of childhood. It is not only modern Western citizens whom Western professionals and governments feel should have a particular sort of childhood, but also worldwide populations who are often viewed as in need of civilisation and development (according to ideals derived from Western psycho-medicine). The export of Western notions of childhood, socialization, and education is inextricably connected to the export of modern Western constructions of gender, individuality, and family amongst other things (Comaroff \& Comaroff, 1991; Stephens, 1995). As particular conceptions of 'normal' childhood are exported so are particular conceptions of 'deviant' childhoods. The perception that many third world children are living deviant childhoods can then be interpreted as local peculiarities and instances of backwardness and under-development thus justifying continued efforts to export Western visions of childhood around the world (Stephens, 1995).

We can see this dynamic occurring in the highest global political bodies. In 1989 the United Nations convention on the rights of the child was adopted by the United Nations general assembly (UN, 1989). The convention was not only a general statement of good intent, but also an instrument that is legally binding to those states that ratified it. More than previous treaties, the convention recognizes the child's capacity to act independently, bestowing not just protective but also enabling rights, such as the right to freedom of expression and association (Cantwell, 1989). According to Jo Boyden (1997) closer scrutiny of the convention shows that it has a strong interest in spreading to the poor countries of the South, the values and codes of practice devised in the public sector of the medico-psychological led visions of childhood of the industrialized North.

In the name of universal children's rights the UN convention asserts one dominant cultural, historical framework. For example, the language of the rights of 'the child' rather than the 
rights of 'children' suggests a universal freestanding individual child on a particular developmental trajectory. Caution is necessary when transplanting the concept of individual rights to societies where the family, not the individual, is considered the basic social unit. While the industrialized North places a high value on the development of the individual and their individuality, for many societies the desire to maintain group solidarity means that individual aspirations are not given the same level of importance. Therefore, what might be considered an abuse of rights in a Northern context (for example not giving a child free choice) may in other countries be perceived as a vital mechanism for maintaining the more highly valued aspiration of group cohesion.

Although raising children's rights as an international issue is potentially of great importance, greater account has to be taken of regional diversity - one universal standard risks causing further colonial oppression (Newman-Black, 1989). When this occurs important and often-conflicting conceptualizations of children's rights emerge. For example, when the Organization of African Unity drew up a charter on the rights and welfare of the child (Organisation of African Unity, 1990), much of the charter was framed in terms of responsibilities and duties of children and families rather than rights and needs of the child. Thus according to the Organization of African Unity's charter every child should have responsibilities towards their family and society, with children viewed as having a duty to work for the cohesion of the family, and to respect their parents, superiors and elders.

Just as problematic notions of child rearing are being imposed on countries of the South, so also are problematic notions of child mental health problems. As mentioned earlier, market economies need to continually expand markets has allowed drug companies to exploit new, vague, and broadly defined childhood psychiatric diagnoses, resulting in a rapid increase in the amount of psychotropic medication being prescribed to children and adolescents in the West. Globalisation means this trend is spreading to countries of the poorer South where growth in the prescribing of psychotropic medications to children is occurring (Wong et al, 2004). This suggests that the Western individualized biological/genetic conception of childhood mental health problems is spreading to the countries of the South and may be undermining more helpful indigenous belief systems (Timimi, 2005a; 2005b).

For the last few decades Western mental health institutions have been pushing the idea of 'mental-health literacy' on the rest of the world. Cultures are viewed as becoming more 'literate' about mental illness the more they adopt Western biomedical conceptions of diagnoses like depression, ADHD, and schizophrenia. This is driven by a belief that modern, 'scientific' approaches reveal the biological and psychological basis of psychic suffering and so provide a rational pathway to dispelling pre-scientific approaches that are often viewed as harmful superstitions. In the process of doing this, it is not only implied that those cultures that are slow to take up these ideas are therefore in some way 'backward', but also disease categories and ways of thinking about mental distress that were previously uncommon in many parts of the world are successfully exported. Thus conditions like depression, post-traumatic stress disorder, and anorexia appear to be spreading across cultures, replacing indigenous ways of viewing and experiencing mental distress (Summerfield, 2008; Watters, 2009). In addition to exporting these beliefs and values, Western drug companies see in such practice the potential to open up new and lucrative markets (Watters, 2009; Petryna et al, 2006). 
Despite copious evidence from research in the non industrialised world, that shows the outcomes for major 'mental illnesses', is consistently better than in the industrialised world and particularly amongst populations who have not had access to drug based treatments, (Hopper et al, 2007; Whitaker, 2009) the World Health Organisation, together with the pharmaceutical industry, has been campaigning for greater 'recognition' of mental illnesses in the non-industrialised world, basing their assumptions on the idea that ICD/DSM descriptions are universally applicable categories (World Health Organisation, 2010). Like other marketing campaigns, this strategy has the potential to open up new markets for psychiatric drugs that maybe ineffective and can have serious side effects, at the same time as painting indigenous concepts of, and strategies to deal with, mental health problems, as being based on ignorance, despite their obvious success for these populations.

A subtler source of impact on cultural beliefs is due to psychiatric diagnoses inadvertently setting standards for 'normality', by categorising what emotional and behavioural traits and experiences should be considered 'disordered'. As the criteria for diagnoses are arrived at by subjective judgments rather than objective evidence (being literally voted in or out of existence by committees), they will have an automatic bias toward the cultural standards found in economically dominant societies (who also tend to control what counts as 'knowledge' globally). This sets in motion a diagnostic system vulnerable to institutional racism in the dominant societies and colonialism in others, as other standards of normality will, at least to some extent, come to be viewed as 'primitive', 'superstitious' etc. and their populations will be viewed as needing to be (psycho)educated. As a result then, for the majority of the world, all manner of complex somatic/emotional complaints have to be recategorised, spiritual explanations have to be denounced, parenting practices viewed as oppressive and so on.

Thus imposing Western medical model DSM/ICD style psychiatry on non-Western populations risks a number of things including: adoption of Western psychiatric notions of 'psychopathology' to express mental distress, undermining of existing cultural strategies for dealing with distress, and the imposition of an individualistic approach that may marginalise family and community resources and divert attention from social injustice.

It is acknowledged by mainstream diagnostic manuals that cultural variations in psychopathology may be found in affective, behavioural, or linguistic expressions of distress, or in the content of disturbed cognitions and sensory experiences (e.g. American Psychiatric Association, 2000). However, the study of these variations in children and adolescents and how they change with increasing age has been largely ignored. Research is needed to investigate culture's role in the development and long-term course of emotional distress and behavioural deviance amongst children and adolescents. Prior to undertaking epidemiological studies, more work is needed to ascertain the ways psychopathology is defined in various cultures (Hoagwood \& Jensen, 1997), including cultural variations in symptom expression and phenomenology (Manson et al, 1997). Despite its acknowledgment of culture's role in psychopathology, the nosological systems (i.e. DSM and ICD) applied currently in research still conceptualizes mental disorder as residing mainly in the individual. Such a nosological system itself emerged from an epistemology that is culturally constituted. The diagnostic criteria and measurement tools currently employed may thus restrict the likelihood of finding differences in prevalence, presentations and prognosis among differing cultural groups. 


\subsection{Stigma}

One often cited reason for exporting Western model psychiatry to the rest of the world is the belief that societies in the developing world stigmatise those who have mental health problems (e.g. World Health Organisation, 2010). A review of the evidence however, shows that stigma maybe more of a problem for Western societies whose institutions support the mainstream medical model view of mental distress and behavioural deviance. Exporting Western psychiatry may thus result in more not less stigma for those in the developing countries who present with mental health problems.

Read et al (2006) carried out a comprehensive review of the literature on stigma and schizophrenia to assess whether the 'schizophrenia is an illness like any other' approach helps reduce prejudice towards those with the diagnosis. They found an increase in biological causal beliefs across Western countries in recent years, but also that biological attributions for psychosis were overwhelmingly associated with negative public attitudes. For example, Angermeyer \& Matschinger (2005) subjected two representative population surveys of public attitudes to psychiatric patients conducted in Germany in 1990 and 2001 to a trend analysis. Over the period of the study an increase in public acceptance of biomedical explanations of psychosis was associated with a public desire for an increased distance from people with schizophrenia.

The 'medical model' of schizophrenia not only increases public stigma, but also contributes to patients internalising an explanatory model that can hinder recovery. For example, it has been found that the presence of 'insight' (in psychiatric terms, meaning accepting the medical model of having a brain illness) in schizophrenia lowers self-esteem, leads to despair and hopelessness, and also predicts higher levels of depression and risk of suicide attempts several years later (Crumlish et al, 2005). Hasson-Ohayon et al (2006) found that the presence of this sort of 'insight' was negatively correlated with emotional well-being, economic satisfaction, and vocational status. The conclusion we may draw from this body of research is that the empowerment of people with mental illness and helping them reduce their internalised sense of stigma are as important as helping them find insight into their illnesses (Warner, 2010). Accepting a diagnosis of schizophrenia means that the person must also accept the negative public attitudes and stigma associated the diagnosis. As this 'medical model' seems to increase internal and external stigma, exporting this worldwide seems like a counterproductive step. Some anthropological evidence supports this stance as it seems that part of the reason why the outcome is better for those who develop a psychotic episode in the developing world is less stigma.

For example, the anthropologist Juli McGruder spent a number of years in Zanzibar studying the families of those diagnosed with schizophrenia. Though the population is predominantly Muslim, Swahili spirit-possession beliefs are still prevalent and commonly evoked to explain the actions of those who violate social norms. McGruder found that far from being stigmatizing, these beliefs served certain useful functions. The beliefs prescribed a variety of socially accepted interventions and ministrations that kept the ill person bound to the family and kinship group. McGruder saw this approach in many small acts of kindness, watching family members use saffron paste to write phrases from the Koran on the rims of drinking bowls so the ill person could literally imbibe the holy words. The spiritpossession beliefs had other unexpected benefits. This way of viewing mental distress allowed the person a cleaner bill of health when the illness went into remission. An ill 
individual enjoying a time of relative mental health could, at least temporarily, retake his or her responsibilities in the kinship group. Since the illness was seen as the work of outside forces, it was understood as an affliction for the sufferer but not as an identity inscribed through unalterable internal factors such as his or her genes (Watters, 2009).

Although emotive images of unacceptable practice in developing countries are often used, such as pictures of persons deprived of their liberty by being tied to a tree or whatnot, we should remember that mental health systems in the West have institutionalised deprivation of liberty through legal means and that mental hospitals often use restraint and rapid tranquilisation, sometimes with fatal consequences - hardly evidence of a more 'humane' system.

\subsection{Globalisation from below- new opportunities}

The politics of neo-liberal globalisation also creates opportunities and paradoxes. Thus, neither the economic or cultural flow has been all one-way. Globalisation has arguably brought many aspects of non-Western cultures, from cuisine to medicinal, and from spiritual to aesthetic into the mainstream. Thus, the centre - periphery model of globalisation cannot account for these other complex, overlapping and disjunctive variations which result in differing regional concerns together with new forms of cultural hybridity and multiplicity (Appadurai, 1993).

Not only does globalisation create the space and possibilities for reverse cultural flow and thus new emerging fusions of identities, beliefs and practices, but, in addition, globalisation can produce resistance and, in some cases, a rediscovery of the importance of certain aspects of traditional culture. For example, despite prolonged attempts at influencing public opinion in Arab Middle East and North Africa, attitudes have, if anything, hardened against Western value systems and there has been a move to reaffirm and strengthen the regional, Muslim, identity (Fernea, 1995; Gregg, 2005). The rapid increase in exposure to global influences may indeed expose children and young people to conflict between contradictory values systems. This conflict can lead to vulnerability and mental health problems, but it can also lead to innovative solutions, and new cross- cultural identities both within the 'outsider' culture and the young of the host community (Banhatti et al, 2006).

\section{Implications}

There has been an increase in psychosocial disorders in children and adolescents in most Western societies. Childhood problems are increasingly medicalised resulting in an apparent 'epidemic' of emotional and behavioural disorders in children in the West and a rapid rise in the prescription of psychotropics to the young. I have summarised the problematic nature (in terms of lack of evidence for a biological substrate, high comorbidity, lack of cross-cultural validity, boundary issues, marginalisation of certain types of evidence, and lack of evidence for effectiveness of medications used) of current popular child psychiatric diagnoses such as ADHD, autism and childhood depression elsewhere (Timimi, 2002; 2004; 2005a; 2008a; 2009b; Timimi \& Maitra, 2006; Timimi et al, 2004; Timimi et al, 2010).

In this chapter I have explored how Western economic, political, and social conditions, often via its effects on the common value system, are contributing to increasing levels of poor 
mental health amongst children, and how potentially valuable alternative models can be found in non-Western traditions. The current professional response of medicalising these complex issues raises many practical, clinical and ethically dilemmas.

Whatever part of conditions such as ADHD are biological (all behaviour ultimately derives from a biological substrate), how we construct meaning out of this is a cultural process. Similarly, Western child protection systems also have problematic aspects. They have developed in the context of protecting the 'individual' child and often involve removal of the child from dangerous/abusive situations. Little legislative attention has been given to strengthening social cohesion and reducing inequality as an important avenue to improving child protection.

Our lack of engagement with alternative perspectives from non-Western traditions reflect a rather hidden form of institutionalized racism (or more accurately, institutionalized cultural hegemony) that has infected Western academic and political endeavours for several centuries. Not only does this present real dangers to the traditions and knowledge bases in existence in the non-Western world, but it also means that populations of the Western world are being denied the opportunity to benefit from the positive effects that giving serious consideration to non-Western knowledge, values and practices may bring.

Ethnographic or observational studies to identify and classify cultural variations in the expression of distress or psychopathology can provide data for hypothesis generation. Other exploratory studies using qualitative, ethnographic, and narrative methods can be used to generate ideas for construct definition and identification of culturally appropriate indices as well as correlates that, in turn, can serve as a basis for measurement construction and generation of alternative nosologies. Quantitative studies using larger, representative samples would follow. More careful consideration should be given to the following question: To what degree is what we find in cross-cultural research, the result of measures that are predicated on premises of the dominant, culturally constituted epistemology? If we have developed a measure with samples dominated by majority culture participants and then apply these measures cross-culturally, and find little difference in prevalence and little variability in the expression of, for example, anxiety, what does this finding mean? By defining, via the measurement instruments, what anxiety is in the majority European/American culture, there is likely to be a restriction of what we allow ourselves to find, and this will increase the likelihood that the disorder will look the same everywhere. For example, in an interesting paper by Jadhav (2007) the diagnostic criteria of an established South Asian culture specific neurosis, 'Dhat' syndrome (which revolves around a fear of semen loss), were deployed by a psychiatrist of South Asian origin, amongst white Britons in London, UK, presenting for the first time with a clinical diagnosis of Depression. Based on both narrative accounts and quantitative scores, Jadhav found a significant subset of white British subjects diagnosed with depression, may in fact be expressing a psychological variation of a previously 'unknown' local White British somatisation phenomena that he labels 'Semen Retention Syndrome'. Jadhav suggests that if you do the reverse of the usual procedure for categorizing mental distress in non-Western societies, substantial numbers of Western patients can be re-categorised into apparent culture bound syndromes, suggesting that Western derived mental health/illness categories commonly in use in psychiatry are just as culture bound. 
Western professional's lack of knowledge about non-Western approaches to children is depriving the West of a rich source of alternative strategies. New ideas to help enrich theory and practice with regards children's mental health can be found in three key areas:

\subsection{Defining problems}

Different cultures see different behaviours as problematic. A model of child development that recognises that different cultures have different (and healthy) versions of child development has the potential to reduce the amount of pathologising of childhood in current Western medical practice and cultural discourse more generally. This requires Western professionals such as child psychiatrists, psychologists, paediatricians, psychotherapists, teachers, and social workers to question the universal validity of the concepts used in relation to children's development and mental health, and the rating questionnaires that accompany them and to accept a greater variety of childhood behaviours, child developmental trajectories, and parenting approaches as being 'normal' (Timimi, 2002; 2005a; 2005b; 2009a).

\subsection{Solving problems}

Western culture has many methods of treating childhood problems, including: family therapy, cognitive behavioural therapy, humanistic therapies, psychodynamic psychotherapy, and drugs. In addition, all communities have valuable resources, including spiritual/religious ones. For many non-Western cultures, the family not the individual is regarded as the basic social unit. Families' strengths and capacity to heal or comfort children can be recognised and promoted (Timimi, 2005a; Maitra, 2006, Banhatti et al, 2006).

Ideas from other systems of medicine may be useful. For example, Ayurvedic medicine sees illness as a disruption in the delicate somatic, climactic, and social system of balance. Causes are not located as such but seen as part of a system out of balance, with symptoms viewed as part of a process rather than a disease entity (Obeyesekere, 1977). Such an attitude based on balance with nature (as opposed to controlling it) has resonance with new approaches that include lifestyle interventions such as diet, exercise, mindfulness, family routines, and systemic psychotherapy all of which can help enhance and diversify clinical practice.

\subsection{Cultural influences on behaviour}

As socially respected practitioners, we have a responsibility to understand that we bring a cultural value system into our work. Our actions will ripple out into the wider local community. For example, if we calm a child's behaviour with drugs, the child's school may understandably refer more children for this treatment, resulting in a ripple effect into beliefs and practices around children's behaviour in that community, thus sparking off of a commodification process that can lead to a deskilling in the school staff and unnecessary exposure of children to potentially harmful medicines that do not improve outcomes in the long term. With regard policy we could support policies likely to promote a more pro-social value system, which limits opportunities for the commodification of children, and that supports stronger more cohesive families and communities. An exhaustive argument about what policies would produce such a change is not within the remit of this chapter. What we do need, however, is a wider debate that engages the public with politicians, in which 
knowledge about children's development, mental health, protection, and their relationship to culture should be included. Suggestions of policy areas that may promote a more prosocial set of values and consequently practices include: fighting global child poverty, support for community based services that use local resources and beliefs, limiting advertising aimed at the young, family friendly business practices such as flexible working hours, and criminalising wilfully absent parents.

\section{Conclusion}

Globalisation is happening in an era when the power relation between the world's rich and poor nations is glaringly unequal. We see this in the arena of health, with grossly disproportionate funds available to rich and poor countries. We also see it in the ideas that shape global approaches to health policy - for example, the World Health Organization continues to advocate the Western model of distress and mental illness as suitable for all countries and cultures- and to childhood.

The challenge for both the theory and practice in child and adolescent mental health is daunting, but there will be rich pickings if it can be met. We must critically re-examine the narrow basis on which current theory and practice has developed. This will help not only other culture's children but also children in the West. Increased knowledge will also make it easier to engage with multi-ethnic communities that have different faith traditions and cultural beliefs from the host society.

\section{References}

American Psychiatric Association. (2000). Diagnostic and statistical manual of mental disorders (4th edition, text review), APA, Washington, DC.

Althusser, L. (1969). For Marx, Allen Lane, London.

Ang, I. (1996). Living Room Wars, Routledge, London.

Angermeyer, M.C., \& Matschinger, H. (2005). Causal beliefs and attitudes to people with schizophrenia. Trend analysis based on data from two population surveys in Germany. British Journal of Psychiatry, 186, 331-334.

Appadurai, A. (1993). Disjuncture and difference in the global cultural economy. In: Colonial Discourse and Post-Colonial Theory, P. Williams \& L. Chrisman (Eds.), Harvester Wheatsheaf, Hemel Hempstead.

Banhatti, R., \& Bhate, S. (2002). Mental health needs of ethnic minority children. In: Meeting the Needs of Ethnic Minority Children, K.N. Dwivedi (Ed.), Jessica Kingsley, London.

Banhatti, R., Dwivedi, K., \& Maitra, B. (2006) Childhood: An Indian perspective. In: Critical Voices in Child and Adolescent Mental Health, S. Timimi \& B. Maitra (Eds.), Free Association Books, London.

Beckett, C. (2005). The Swedish myth: Corporal punishment ban and child death statistics. British Journal of Social Work, 35, 125-138.

Bhagwat, B.K. (2002). Foreword. In: Child Care in Ancient India From the Perspectives of Developmental Psychology and Paediatrics, M. Kapur \& H. Mukundan, Sri Satguru Publications, Delhi.

Boyden, J. (1997). Childhood and the policy makers: a comparative perspective on the globalization of childhood. In: Constructing and Reconstructing Childhood, A. James \& A. Prout (Eds.), Falmer Press, London. 
British Medical Association. (2006). Child and Adolescent Mental Health: A Guide for Professionals, BMA, London.

Burman E. (2005). Childhood, neo-liberalism and the feminization of education. Gender and Education, 17, 351-367.

Calvert, K. (1992) Children in the House: The Material Culture of Early Childhood, 1600-1900, Northeastern University Press, Boston.

Cantwell, N. (1989). A tool for the implementation of the UN convention. In: Making Reality of Children's Rights, R. Barnen (Ed.), UNICEF, New York.

Castree, N. (2001). Commodity fetishism: Geographical imaginations and imaginative geographies. Environment and Planning, 33, 1519-1525.

Comaroff, J. \& Comaroff, J. (1991). Africa observed: Discourses of the imperial imagination. In: Of Revelation and Revolution: Christianity, Colonialism and Consciousness in South Africa, Vol. 1, J. Comaroff \& J. Comaroff (Eds.), University of Chicago Press, Chicago.

Cederblad, M. (1988). Behavioural disorders in children from different cultures. Acta Psychiatrica Scandinavia, 78(S344), 85-92.

Cook, R.J., Dickens, B.M. \& Fathalla, M.F. (2002). Female genital cutting (mutilation/circumcision): Ethical and legal dimensions. International Journal of Gynecology and Obstetrics, 79, 281-287.

Crumlish, N., Whitty, P., \& Kamali, M. (2005). Early insight predicts depression and attempted suicide after 4 years in first-episode schizophrenia and schizophreniform disorder. Acta Psychiatrica Scandinavica, 112, 449 - 455.

Davis, S.S., \& Davis, D.A. (1989) Adolescence in a Moroccan Town, Rutgers University Press, New Brunswick.

Department of Health, NHSE (2005) Prescription Cost Analysis England 2004. Available at http://www.dh.gov.uk/PublicationsAndStatistics/Publications/PublicationsStatis tics/PublicationsStatisticsArticle/fs/en?CONTENT_ID $=4107504 \& c h k=n s v F E 0$

Dodds, C. (2005). Latest NICE Guidelines Sets New Standards for Treating Depression in Children and Young People. Available http://www.nice.org.uk/pdf/2005_022_Depression_in_Children_Guideline.pdf

Double, D. (2002). The limits of psychiatry. British Medical journal, 324, 900-904.

Dwivedi, K.N. (1996). Culture and Personality. In: Meeting the Needs of Ethnic Minority Children, K.N. Dwivedi \& V.P. Varma (Eds.), Jessica Kingsley, London.

Fernea, E.W. (Ed.) (1995). Children in the Muslim Middle East, University of Texas Press, Austin.

Finkelhor, D., \& Korbin, J. (1988). Child abuse as an international issue. Child Abuse and Neglect, 12, 3-23.

Friedli, L. (2009). Mental Health, Resilience and Inequalities: How Individuals and Communities are Affected, World Health Organisation, Copenhagen.

Giddens, A. (1990). The Consequences of Modernity, Polity Press, Cambridge.

Giddens, A. (1991). Modernity and Self-Identity, Polity Press, Cambridge.

Gil'adi, A. (1992). Children Of Islam: Concepts Of Childhood In Medieval Muslim Society, MacMillan, Oxford.

Gregg, G.S. (2005). The Middle East: A Cultural Psychology, Oxford University Press, New York.

Hackett, L., \& Hackett, R. (1994). Child rearing practices and psychiatric disorder in Gujarati and British children. British Journal of Social Work, 24, 191-202.

Hasson-Ohayon, H., Kravetz, S., Roe, D., David, A.S., \& Weiser, M. (2006). Insight into psychosis and quality of life. Comprehensive Psychiatry, 47, 265-269. 
Harkness, S., \& Super, C. (Eds.) (1996). Parents' Cultural Belief Systems: Their Origins, Expressions and Consequences, Guilford Press, London.

Harvey, D. (2010). A companion to Marx's Capital, Verso, London.

Hoagwood, K., \& Jensen, P. (1997). Developmental psychopathology and the notion of culture. Applied Developmental Science, 1, 108-1 12.

Hofstede, G. (1994). Cultures and Organisations: Software of the Mind, Harper-Collins, London.

Hopper, K., Harrison, G., Janka, A., \& Sartorius, N. (Eds.) (2007). Recovery from Schizophrenia: An International Perspective, Oxford University Press, Oxford.

Jadhav, S. (2007). Dhis and Dhat: Evidence of semen retention syndrome amongst white Britons. Anthropology and Medicine, 14, 229-239.

James, O. (2007). Affluenza, Vermilion, London.

Kakar, S. (1994). The Inner World of the Indian Child, Oxford University Press, New Delhi.

Kakar, S. (1997). The Inner World: A Psychoanalytic Study of Childhood and Society in India (Second Edition), Oxford University Press, New Delhi.

Kaplan, E. (1997). Looking for the Other: Feminism, Film and Imperial Gaze, Routledge, London.

Lari, A., Alaghehbandan, R., \& Joghataei, M. (2005). Psychosocial and cultural motivations for self-inflicted burns among Iranian women. International Psychiatry, 9, 5-6.

LeFever, G.B., Dawson, K.V., \& Morrow, A.D. (1999) The extent of drug therapy for attention deficit hyperactivity disorder among children in public schools. American Journal of Public Health, 89, 1359-1364.

LeVine, R.A., Dixon, S., LeVine, S., Richman, A., Leiderman, P.H., Keefer, C.H., \& Brazelton, T.B. (1994) Child Care and Culture: Lessons from Africa, Cambridge University Press, Cambridge.

Maitra, B. (1996). Child abuse: A universal diagnostic category? The International Journal of Social Psychiatry, 42, 287-304.

Maitra, B. (2006). Culture and the mental health of children: The cutting edge of expertise. In: Critical Voices in Child and Adolescent Mental Health, S. Timimi \& B. Maitra (Eds.), Free Association Books, London.

Manson, S. M., Bechtold, D. W., Novins, D. K., \& Beals, J. (1997). Assessing psychopathology in American Indian and Alaska Native Children and Adolescents. Applied Developmental Science, 1, 135-144.

Martin, J., \& Sugarman, J., (2000). Between the modern and the postmodern: the possibility of self and progressive understanding in psychology. American Psychologist, 55, 397406.

McMunn, A.N., Nazroo, J.Y., Marmot, M.G., Boreham, R., \& Goodman, R. (2001) Children's emotional and behavioural well-being and the family environment: findings from the Health Survey for England. Social Science and Medicine, 53, 423-440.

Moncrieff, J. (2008) Neoliberalism and biopsychiatry: A marriage of convenience. In: Libratory Psychiatry: Philosophy, Politics and Mental Health, C. Cohen \& S. Timimi (Eds.), Cambridge University Press, New York.

NHS Information Centre. (2010). Prescription Cost Analysis, England - 2009, available from: http://www.ic.nhs.uk/webfiles/publications/prescostanalysis2009/PCA_2009.pd $\mathrm{f}$

National Institute of Drug Abuse. (2011). Prescription Drug Abuse, available from: http://www.nida.nih.gov/tib/prescription.html

Newman-Black, M. (1989). How can the convention be implemented in developing countries? In: Making Reality of Children's Rights, R. Barnen (Ed.), UNICEF, New York.

Obeyesekere, G. (1977). The theory and practice of psychological medicine in Ayurvedic tradition. Culture, Medicine and Psychiatry, 1, 155-181. 
Olfson, M., Marcus, S.C., Weissman, M.M., \& Jensen, P.S. (2002) National trends in the use of psychotropic medications by children. Journal of the American Academy of Child and Adolescent Psychiatry, 41, 514-21.

Organization of African Unity, (1990). The African Charter on the Rights and Welfare of the Child Adopted by the 26th Ordinary Session of the Assembly of Heads of State and Government of the OAU, OAU, Addis Ababa.

Petryna, A., Lakoff, A., \& Kleinman, A. (2006) Global Parmaceuticals: Ethics, Markets, Practices, Duke University Press, Durham.

Pillai, A., Patel, V., Cardozo, P., Goodman, R., Weiss, H.A., \& Andrew, G. (2008) Nontraditional lifestyles and prevalence of mental disorders in adolescents in Goa, India. The British Journal of Psychiatry, 192, 45-51.

Prout, A., \& James, A. (1997). A new Paradigm for the sociology of childhood? Provenance, promise and problems. In: Constructing And Re-Constructing Childhood: Contemporary Issues In The Sociological Study Of Childhood, A. James, \& A. Prout (Eds.), Falmer Press, London.

Read, J., Haslam, N., Sayce, L., \& Davies, E. (2006). Prejudice and schizophrenia: A review of the 'Mental illness is an Illness like any other' approach. Acta Psychiatrica Scandinavica, 114, 303-318.

Richards, B. (1989). Visions of freedom. Free associations, 16, 31-42.

Robertson, M.M. (2000). No net loss: Wetland restoration and the incomplete capitalization of nature. Antipode, 32, 463-493.

Rose, N. (1999). Powers of Freedom: Reframing Political Thought, Cambridge University Press, New York.

Roland, A. (1980). Psychoanalytic perspectives on personality development in India. International Review of Psychoanalysis, 1, 73-87.

Segal, U. (1992). Child abuse in India: An empirical report on perceptions. Child Abuse and Neglect, 16, 887-908.

Sharav, V. (2006). ADHD Drug Risks: Cardiovascular and Cerebrovascular Problems. Available from: http://www.ahrp.org/cms/content/view/76/28/

Slater, D. (1997). Consumer Culture and Modernity, Polity, Cambridge.

Smith, R. (2003). An extreme failure of concordance. British Medical Journal, 327, 819.

Stephens, S. (1995) Children and the politics of culture in "Late Capitalism". In: Children and The Politics Of Culture, S. Stephens (Ed.) Princeton University, Press Princeton.

Summerfield, D. (2008). How scientifically valid is the knowledge base of global mental health? British Medical Journal, 336, 992-994.

Tait, G. (2006). A brief philosophical examination of ADHD. In: Critical New Perspectives on $A D H D$, G. Lloyd, J. Stead, \& D. Cohen (Eds.), Routledge, Abingdon.

Timimi, S. (2002). Pathological Child Psychiatry and the Medicalization of Childhood, BrunnerRoutledge, London.

Timimi, S. (2004). Rethinking childhood depression. British Medical Journal, 329, 1394-1396.

Timimi, S. (2005a). Naughty Boys: Anti-Social Behaviour, ADHD, and the Role of Culture, Palgrave Macmillan, Basingstoke.

Timimi, S. (2005b). Effect of globalisation on children's mental health. British Medical Journal, 331, 37-39.

Timimi, S. (2008a). Child psychiatry and its relationship to the pharmaceutical industry: Theoretical and practical issues. Advances in Psychiatric Treatment, 14, 3-9.

Timimi, S. (2008b). Children's mental health and the global market: an ecological analysis. In: Libratory Psychiatry: Philosophy, Politics and Mental Health, C. Cohen \& S. Timimi (Eds.), Cambridge University Press, New York. 
Timimi, S. (2009a). A straight Talking Introduction to Children's Mental Health Problems, PCCS Books, Ross-on-Wye.

Timimi, S. (2009b). The use of psycho-pharmaceuticals to control boys' behaviour: A tale of badly behaving drug companies and doctors. Arab Journal of Psychiatry, 20, 147 - 160.

Timimi, S. (2009c). The commercialization of children's mental health in the era of globalization. International Journal of Mental Health, 38, 5 - 27.

Timimi, S. (2010). The McDonaldization of childhood; Children's mental health in neoliberal market cultures Transcultural Psychiatry, 47, 686-706.

Timimi, S., \& Dwivedi, K. (2009) Child and adolescent psychiatry. In: Psychiatry - An Evidence Based Text for the MRCPsych, B. Puri \& I. Treasaden (Eds.), Hodder-Arnold, London.

Timimi, S., \& Maitra, B. (Eds.) (2006). Critical Voices in Child and Adolescent Mental Health, Free Association Books, London.

Timimi, S., \& 33 co-endorsers. (2004). A critique of the international consensus statement on ADHD. Clinical Child and Family Psychology Review, 7, 59-63.

Timimi, S., Gardiner, N., \& McCabe, B. (2010). The Myth of Autism: Medicalising Men's and Boys' Social and Emotional Competence, Palgrave MacMillan, Basingstoke.

Triandis, H.C. (1995). Individualism and Collectivism, Westview Press, Boulder.

Trommsdorff, G. (2002). An eco-cultural and interpersonal relations approach to development of the lifespan. In: Online Readings in Psychology and Culture (Unit 12, Chapter 1), W.J. Lonner, D.L. Dinnel, S.A. Hayes, \& D.N. Sattler (Eds.), Center for Cross-Cultural Research, Western Washington University, Washington DC.

UNICEF. (2001). A League Table of Child Deaths by Injury in Rich Nations. UNICEF Innocenti Research Centre, Florence.

UNICEF. (2007). An Overview of Child Well-Being in Rich Countries, UNICEF Innocenti Research Centre, Florence.

UNICEF. (2011). Child Well-Being in the UK, Spain and Sweden: The Role of Inequality and Materialism. Available from:

http://www.unicef.org.uk/Documents/Publications/UNICEFIpsosMori_childwel lbeing_reportsummary.pdf

United Nations General Assembly. (1989). Adoption of a Convention on the Rights of the Child, United Nations, New York.

University of Washington. (2011). Less depression for working moms who expect that they 'can't do it all'. ScienceDaily, August 25, 2011. Available from: http:/ / www.sciencedaily.com/releases/2011/08/110820135309.htm

Warner, R. (2010) Does the scientific evidence support the recovery model? The Psychiatrist, 34, 3-5.

Watters, E. (2009). Crazy like us: The Globalization of the American Psych, Free Press, New York.

Whitaker, R. (2010). Anatomy of an Epidemic, Crown, New York.

Wolfenstein, M. (1955). Fun morality: An analysis of recent child-training literature. In: Childhood in Contemporary Culture, M. Mead \& M. Wolfenstein (Eds.), The University of Chicago Press, Chicago.

Wong, I.C., Murray, M.L., Camilleri-Novak, D., \& Stephens, P. (2004) Increased prescribing trends of paediatric psychotropic medications. Archives of Disease in Childhood, 89, 1131-2.

World Health Organisation. (2010). mhGAP Intervention Guide, WHO, Geneva.

Zito, J.M., Safer, D.J., Dosreis, S., Gardner, J.F., Boles, J., \& Lynch, F. (2000) Trends in prescribing of psychotropic medication in pre-schoolers. Journal of the American Medical Association, 283, 1025-30. 


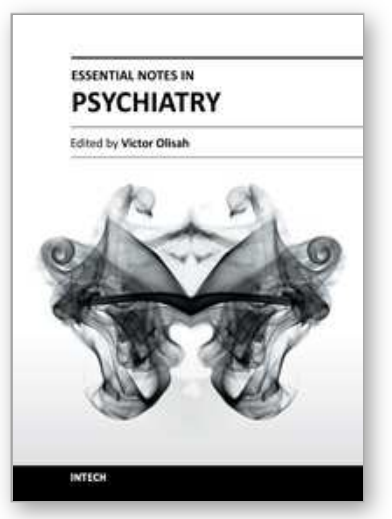

\author{
Essential Notes in Psychiatry \\ Edited by Dr. Victor Olisah
}

ISBN 978-953-51-0574-9

Hard cover, 580 pages

Publisher InTech

Published online 27, April, 2012

Published in print edition April, 2012

Psychiatry is one of the major specialties of medicine, and is concerned with the study and treatment of mental disorders. In recent times the field is growing with the discovery of effective therapies and interventions that alleviate suffering in people with mental disorders. This book of psychiatry is concise and clearly written so that it is usable for doctors in training, students and clinicians dealing with psychiatric illness in everyday practice. The book is a primer for those beginning to learn about emotional disorders and psychosocial consequences of severe physical and psychological trauma; and violence. Emphasis is placed on effective therapies and interventions for selected conditions such as dementia and suicide among others and the consequences of stress in the workplace. The book also highlights important causes of mental disorders in children.

\title{
How to reference
}

In order to correctly reference this scholarly work, feel free to copy and paste the following:

Sami Timimi (2012). Children's Mental Health in the Era of Globalisation: Neo-Liberalism, Commodification, McDonaldisation, and the New Challenges They Pose, Essential Notes in Psychiatry, Dr. Victor Olisah (Ed.), ISBN: 978-953-51-0574-9, InTech, Available from: http://www.intechopen.com/books/essential-notes-inpsychiatry/children-s-mental-health-in-the-era-of-globalisation-neoliberalism-commodification-mcdonaldisat

\section{INTECH}

open science | open minds

\section{InTech Europe}

University Campus STeP Ri

Slavka Krautzeka 83/A

51000 Rijeka, Croatia

Phone: +385 (51) 770447

Fax: +385 (51) 686166

www.intechopen.com

\section{InTech China}

Unit 405, Office Block, Hotel Equatorial Shanghai

No.65, Yan An Road (West), Shanghai, 200040, China

中国上海市延安西路65号上海国际贵都大饭店办公楼 405 单元

Phone: +86-21-62489820

Fax: +86-21-62489821 
(C) 2012 The Author(s). Licensee IntechOpen. This is an open access article distributed under the terms of the Creative Commons Attribution 3.0 License, which permits unrestricted use, distribution, and reproduction in any medium, provided the original work is properly cited. 